\title{
Study on the Design Method of Impeller on Low Specific Speed Centrifugal Pump
}

\author{
Jianhua Liu ${ }^{*}, 1$, Xiangyang Zhao ${ }^{2}$ and Miaoxin Xiao ${ }^{1}$ \\ ${ }^{I}$ Mechanical Engineering Institute, Xinxiang University, Eastern Jin Sui avenue, Xinxiang 453003, China. \\ ${ }^{2}$ Department of Automobile Engineering, Henan Mechanical and Electrical Engineering College, Ping Yuan Rd. \\ Xinxiang 453003, China
}

\begin{abstract}
In this work, the comparative study has been done for five kinds of design methods of the low specific speed centrifugal pump impeller adopted numerical simulation method by software of Fluent, so that the problems can be solved. Many different design methods exists for the low specific speed centrifugal pump impeller, which caused the design effect difficult to control. The numerical simulation method based on the Reynolds time averaged N-S equations (RANS) and RNG $\kappa-\varepsilon$ turbulence models. Results revealed the inner flow pattern of these impeller, and these results were verified by external characteristic experiment. The research results showed that the design method, which adopted compound impeller with short blades and these short blades turned to the suction surface of long blades. Results proved that its flow distribution is even and external characteristic curve is more ideal.
\end{abstract}

Keywords: Design method, impeller, low specific speed centrifugal pump, numerical simulation.

\section{INTRODUCTION}

As a kind of general-purpose fluid machinery, low specific speed centrifugal pump is widely used in aerospace, petrochemical industry, light industry and other fields. Its technical performance affects the various related industries. Since the 1970s, scholars at home and abroad have conducted a lot of related research respectively based on the external characteristic experiment, speed coefficient method and the potential flow theory analysis, and many valuable results have been achieved [1-6].

These research results have been applied in production. But at present a design method accepted by all designers is not available. Now the common design methods of low specific speed centrifugal pump have the velocity coefficient design method, low specific speed design method, compound blades design method, etc. These are based on experience or the results of the potential flow analysis [3-6]. So these methods cause some problem for low specific speed centrifugal such as lower efficiency, internal flow instability and so on. With the rapid development of computer technology and the continuous improvement of the calculation method, numerical simulation has become an important research means in inner flow analysis and design optimization for centrifugal pump. Numerical simulation method and experimental means were used respectively to carry on the comparative study on five type of low specific speed centrifugal pump impeller designed by different design method with the same design parameters.
The purpose of the study is to reveal the structure characteristics of their flow field and provide theoretical basis for design and optimization of centrifugal pump impeller.

\section{THE DESIGN OF THE MODEL PUMP}

The design parameters selected are as follows: $\mathrm{Q}=25 \mathrm{~m} 3 / \mathrm{h}$, $\mathrm{H}=10 \mathrm{~m}, \mathrm{n}=1450 \mathrm{r} / \mathrm{min}$. In this study five types of impeller were designed. To save cost of production and shorten production phase, the same pump body was used in every design scheme, When testing only the impeller needed to be replaced for the model pump. The design results are shown in Table $\mathbf{1}$ for every type of impeller. The structure diagrams of impeller are shown in Figs. $(\mathbf{1}, \mathbf{2})$. Where $\mathrm{Q}$ is pump flow; $\mathrm{H}$ stands for pump head; $\mathrm{n}$ represents pump speed.

\section{TURBULENT FLOW FIELD NUMERICAL SIMULATION ON THE DESIGN IMPELLERS BASED ON EVERY PROGRAM}

\subsection{Three-Dimensional Entity Modeling and Meshing for Calculation Area}

During studying on a single impeller, the physical area of solving area was processed as follows. Firstly, it was assumed that internal flow of the impeller belong to symmetrical, so a single passage was just taken as the solution area between two adjacent blades and impeller's import and export region. Secondly, impeller entrance location was extended appropriately to reduce the impact on solving area from flow of import. Then, in the Pro/Engineer environment, three-dimensional entity model of the impeller's solving area was considered for the five kinds of design scheme. In the software of Gambit three-dimensional 
Table 1. The calculation of pump impeller design.

\begin{tabular}{|c|c|c|c|}
\hline Items & Design Parameters & Design Calculations & Design Results \\
\hline \multirow{3}{*}{$\begin{array}{l}\text { The calculation of } \\
\text { general parameters }\end{array}$} & Specific speed $n_{s}$ & $n_{s}=3.65 n \sqrt{Q} / H^{0.75}$ & 78 \\
\hline & Hub diameter $d_{h}$ & $d_{h}$ based on the size of connection shaft & $40 \mathrm{~mm}$ \\
\hline & Inlet diameter of impeller $D_{j}$ & $D_{j}=\sqrt{D_{0}^{2}+d_{h}^{2}}$ & $75 \mathrm{~mm}$ \\
\hline \multirow{3}{*}{$\begin{array}{l}\text { Scheme1, the low } \\
\text { specific speed design } \\
\text { method }\end{array}$} & Outlet diameter of impeller $D_{2}$ & $D_{2}=1.05 \times(9.35 \sim 9.6) \times\left(n_{s} / 100\right)^{-0.5} \times \sqrt[3]{1.35 Q / n}=187 \sim 192 \mathrm{~mm}$ & Take $188 \mathrm{~mm}$ \\
\hline & Outlet width of blade $b_{2}$ & $b_{2}=0.000375 n_{s}^{1.15} D_{2}=10.6 \mathrm{~mm}$ & Take $12 \mathrm{~mm}$ \\
\hline & others parameters & $\begin{array}{c}\text { Blade inlet angle } \beta_{1}: \beta_{1}=23.4^{\circ} \\
\text { Blade outlet angle } \beta_{2}: \beta_{2}=20 \\
\text { Blade quantity } Z \text { and scroll of blade } \varphi: Z=4, \varphi=160^{\circ}\end{array}$ & \\
\hline \multirow{3}{*}{$\begin{array}{l}\text { Scheme2, Speed } \\
\text { coefficient design } \\
\text { method }\end{array}$} & Outlet diameter of impeller $D_{2}$ & $D_{2}=(9.35 \sim 9.6) \times\left(n_{s} / 100\right)^{-0.5} \times \sqrt[3]{Q / n}=178 \sim 183 \mathrm{~mm}$ & Take $180 \mathrm{~mm}$ \\
\hline & Outlet width of blade $b_{2}$ & $b_{2}=(0.64 \sim 0.7) \times\left(n_{s} / 100\right)^{5 / 6} \times \sqrt[3]{Q / n}=8.7 \sim 9.6 \mathrm{~mm}$ & Take $9 \mathrm{~mm}$ \\
\hline & others parameters & $\begin{array}{c}\text { Blade inlet angle } \beta_{1}: \beta_{1}=29.5^{\circ} ; \\
\text { Blade outlet angle } \beta_{2}: \beta_{2}=41^{\circ} ; \\
\text { Blade quantity } Z \text { and scroll of blade } \varphi: Z=6, \varphi=80^{\circ}\end{array}$ & \\
\hline $\begin{array}{l}\text { Scheme3, Rotor-splitter } \\
\text { blades design method }\end{array}$ & \multicolumn{3}{|c|}{$\begin{array}{l}\text { The blade arrangement adopt Alternative Arrangement structure for three long blade and three short blade, inlet diameter of } \\
\text { short blade equal to 0.7D2 without deflection. }\end{array}$} \\
\hline $\begin{array}{l}\text { Scheme4, Rotor-splitter } \\
\text { blades design method }\end{array}$ & \multicolumn{3}{|c|}{ Short blade do $10^{\circ}$ deflection to pressure surface of the long blade based on the scheme 3 . } \\
\hline $\begin{array}{l}\text { Scheme5, Rotor-splitter } \\
\text { blades design method }\end{array}$ & \multicolumn{3}{|c|}{ The short blade deflects $10^{\circ}$ to the suction surface of the long blade based on scheme 3 . } \\
\hline
\end{tabular}

unstructured grid was generated by block coupling method, and it was carried on partial encryption processing near leaf area. The results of the meshing is as follows: it is number of 82974 in program 1, number of 62884 in program 2, 86703 in program 3, 91808 in program 4 and 86119 in program 5. To save space in this paper, we have only considered grid graph of plan 5 impeller as presented in Fig. (3).

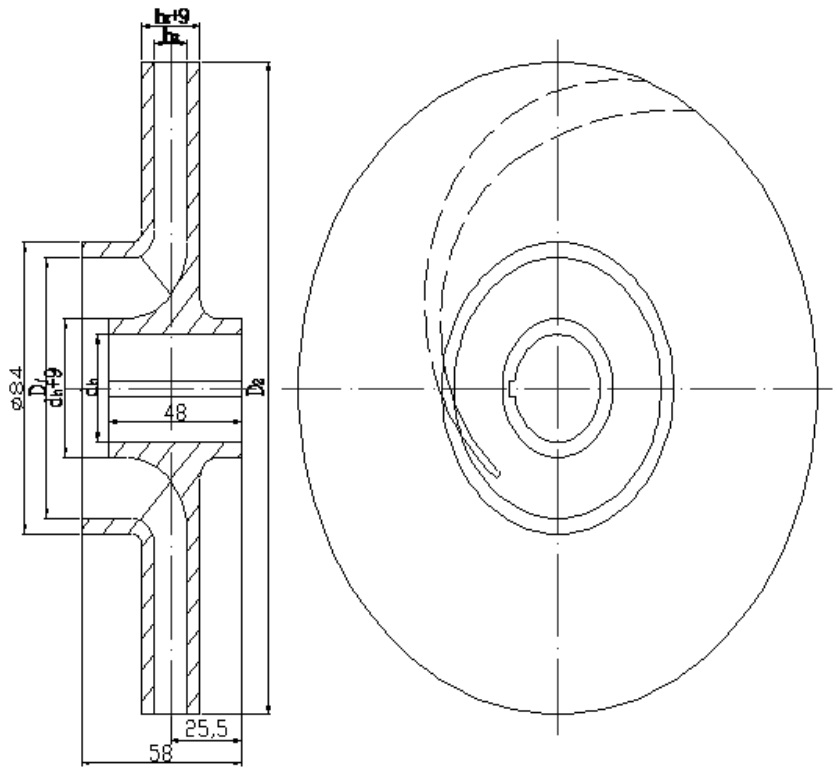

Fig. (1). Design structure diagram of program 1 and 2.

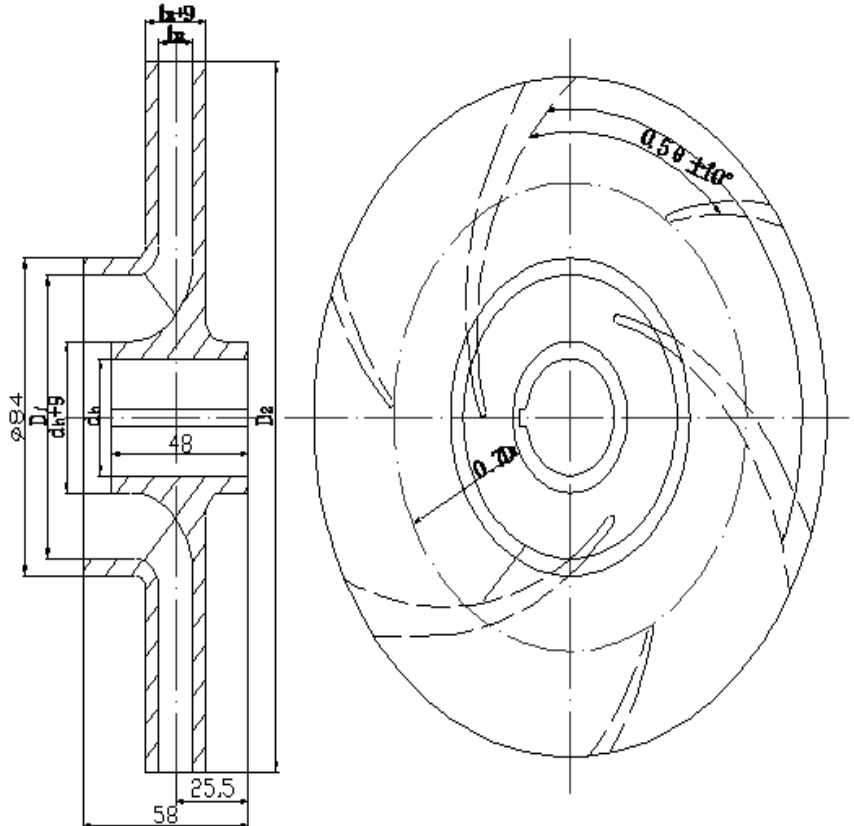

Fig. (2). Design structure diagram of program 3, 4 and 5.

\subsection{Control Equation}

Control equation adopted the Reynolds time averaged N$\mathrm{S}$ equations (RANS), and enclosed by RNG k- $\varepsilon$ turbulence model. 


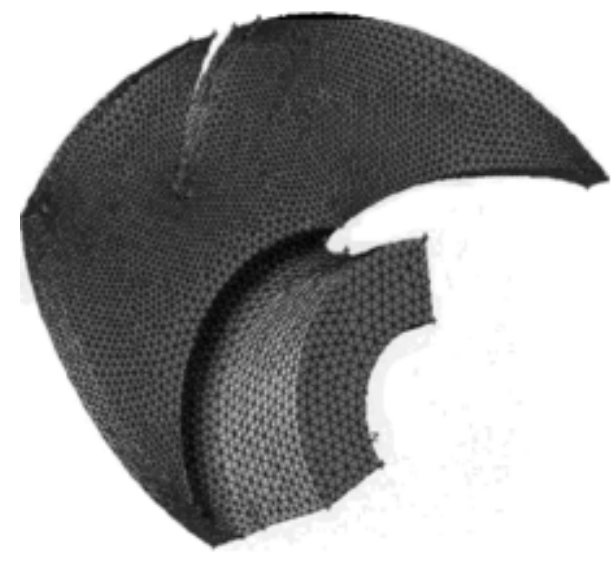

Fig. (3). The grid of the impeller in plan 5.

The control equation can be expressed as follows:

$$
\begin{aligned}
& \frac{\partial}{\partial t}\left(\rho u_{i}\right)+\frac{\partial}{\partial j}\left(\rho u_{i} u_{j}\right)=-\frac{\partial p}{\partial x_{i}}+\frac{\partial}{\partial x_{j}}\left(\mu \frac{\partial u_{i}}{\partial x_{j}}-\rho \bar{u}_{i}^{\prime} \bar{u}_{j}^{\prime}\right)+S_{i} \\
& \frac{\partial(\rho k)}{\partial t}+\frac{\partial\left(\rho k u_{i}\right)}{\partial x_{i}}=\frac{\partial}{\partial x_{j}}\left(\alpha_{k} \mu_{e f f} \frac{\partial k}{\partial x_{j}}\right)+G_{k}-\rho \varepsilon \\
& \frac{\partial(\rho \varepsilon)}{\partial t}+\frac{\partial\left(\rho \varepsilon u_{i}\right)}{\partial x_{i}}=\frac{\partial}{\partial x_{j}}\left(\alpha_{\varepsilon} \mu_{e f f} \frac{\partial \varepsilon}{\partial x_{j}}\right)+C_{1 \varepsilon}^{*} \frac{\varepsilon}{k} G_{k}-C_{2 \varepsilon} \rho \frac{\varepsilon^{2}}{k}
\end{aligned}
$$

where: $\rho$ is the density of the fluid, $u_{i}$ is the velocity vector projection in the direction of $i, u_{j}$ is the velocity vector projection in the direction of $\mathrm{j}, \mathrm{p}$ is fluid pressure, $\mu$ is dynamic viscosity of the fluid, $\rho \bar{u}_{i}^{\prime} \bar{u}_{j}^{\prime}$ is the Reynolds stress, $\mathrm{S}_{\mathrm{i}}$ is generalized source term projection in the direction of $\mathrm{I}$, $\mathrm{k}$ is the turbulent kinetic energy, $\mu_{\mathrm{eff}}$ is effective viscosity coefficient, $G_{k}$ is the turbulent kinetic energy generation caused by the average velocity gradient, $\varepsilon$ is $\mathrm{t}$ urbulent kinetic energy dissipation rate, $\alpha_{\varepsilon}, C^{*}{ }_{1 \varepsilon}$ and $C^{*}{ }_{2 \varepsilon}$ is empirical coefficient.

\subsection{The Boundary Conditions}

There exists mainly import boundary, export boundary and the solid wall boundary in calculation region.

Inlet boundary condition adopted velocity inlet. It is assumed that the axial velocity belongs to uniform distribution on the inlet boundary, and there did not exist the tangential velocity and radial velocity. Speed was given which is perpendicular to the inlet boundary surface. The outlet boundary condition adopted outflow. The solid wall boundary condition applied non-slip condition on wall and wall-function method close to wall area. There existed two periodic boundary when cutting out the calculation region, and there is no pressure drop on the interception, which rotate on the periodic boundary.

\subsection{Numerical Simulation Results and Comparison Analysis}

Five impellers based on different design scheme were simulated in ten flow conditions, which is $5 \mathrm{~m}^{3} / \mathrm{h}, 10 \mathrm{~m} 3 / \mathrm{h}$,
$15 \mathrm{~m} 3 / \mathrm{h}, 20 \mathrm{~m} 3 / \mathrm{h}, 25 \mathrm{~m} 3 / \mathrm{h}, 30 \mathrm{~m} 3 / \mathrm{h}, 35 \mathrm{~m} 3 / \mathrm{h}, 40 \mathrm{~m} 3 / \mathrm{h}, 45 \mathrm{~m} 3 / \mathrm{h}$ and $50 \mathrm{~m} 3 / \mathrm{h}$. In the paper, results of numerical simulation were just given respectively in the small flow which value is $10 \mathrm{~m} 3 / \mathrm{h}$, design discharge which value is $25 \mathrm{~m} 3 / \mathrm{h}$ and heavy discharge which value is $40 \mathrm{~m} 3 / \mathrm{h}$. While the internal flow field data from numerical simulation were analyzed respectively.

\subsubsection{The Relative Velocity Distribution}

The relative velocity distribution is shown from Figs. (48). Its value on the cross section under different working conditions is based on the different design scheme. According to analyzation based on relative velocity field under different working conditions, the analysis results are given as follows for the impeller in plan 1. Internal flow field is basic uniform under each flow conditions. Fluid particles move along the blade type line generally, and the biggish flow velocity comes out near the suction surface in impeller passage. There is a low speed area in distance of about $1 / 3$ from the head on blade pressure surface under each flow conditions, and the low speed region is gradually reduced with the increase of flow. There is no wake zone with low speed in suction side for the impeller outlet side.

For the impeller in plan 2, under the small flow conditions, internal flow field distribution is relatively uniform in the impeller passage, there exists a smaller vortex area with low speed in distance of about $1 / 6$ from the head on blade pressure surface side. There exists a wake zone with low speed in suction side for the impeller outlet side. Under the design flow conditions, there exists an obviously high speed zone in the blade inlet side of the suction side, the highest velocity exists in the suction side of the blade inlet side, which value is about $7 \mathrm{~m}^{3} / \mathrm{s}$, there exists a smaller vortex area with low speed in distance of about 1/6 from the head on blade pressure surface side, there exists a major vortex area with low speed in distance of about $1 / 3$ from the head on blade pressure surface side, while the low-speed wake zone exited in export of blade suction surface became narrowed. Under the heavy flow conditions, the low-speed wake zone exited in blade pressure surface side doesn't shrink basicly, while it just moves slightly towards the exit direction, but the low-speed wake zone exited at export of blade suction surface is disappeared.

For the impeller in plan 3, internal flow field is not uniform under each flow conditions. Under the small flow conditions, there exists an obvious vortex area with low speed in the impeller passage near inlet of blade pressure. The highest velocity exists near the suction side of the long blade. Fluid particle have transverse flow from long blade suction surface to the pressure side. Under the design flow conditions, there existed high speed zone in suction surface side of the long blade and short blade, while there existed larger range of low speed area in suction surface of short blades and pressure surface of long blades. The vortex area shrinked in head of the long blades near pressure side, the biggish velocity in the passageway still appeared on long blade near the suction side, fluid particle still have transverse flow from long blade suction surface to the pressure side. Under the heavy flow conditions, basicly low speed vortex area disappears in the passageway inlet, while fluid particle 

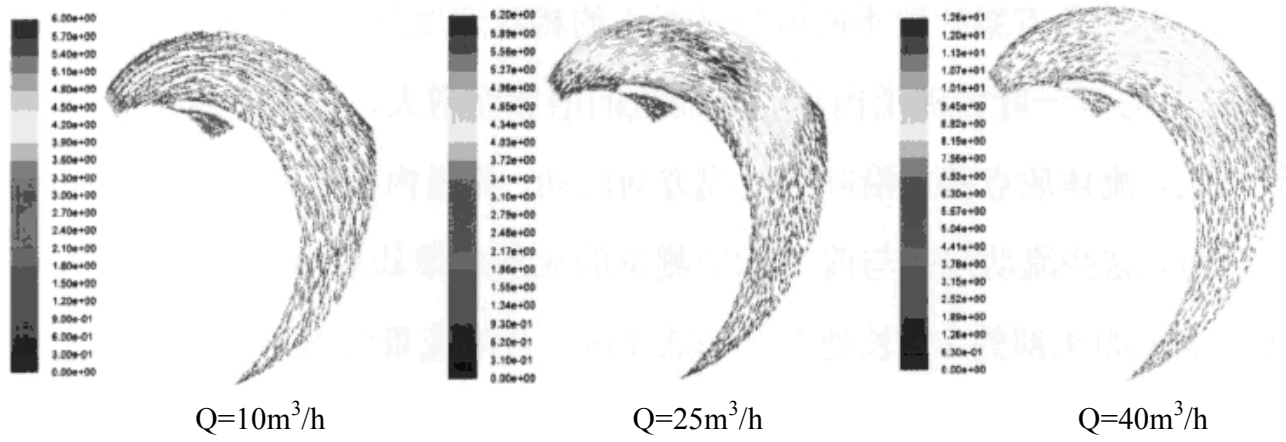

Fig. (4). The relative velocity distribution on the cross section under different working conditions based on plan 1.
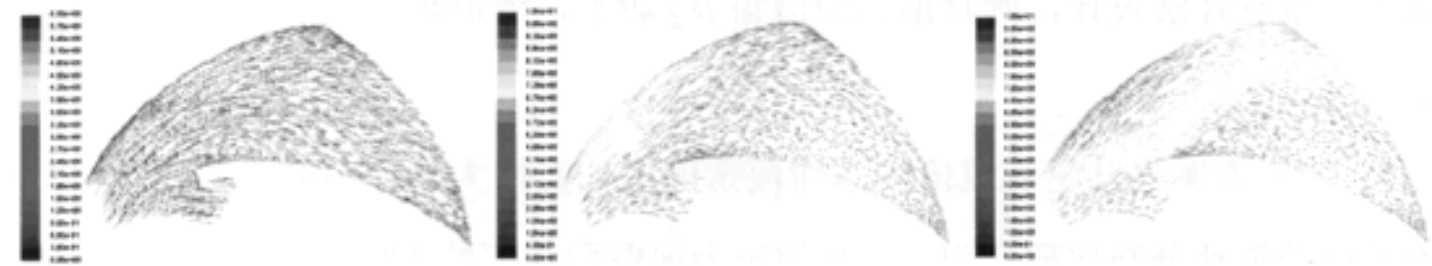

$$
\mathrm{Q}=10 \mathrm{~m}^{3} / \mathrm{h}
$$

$\mathrm{Q}=25 \mathrm{~m}^{3} / \mathrm{h}$

$\mathrm{Q}=40 \mathrm{~m}^{3} / \mathrm{h}$

Fig. (5). The relative velocity distribution on the cross section under different working conditions based on plan 2 .
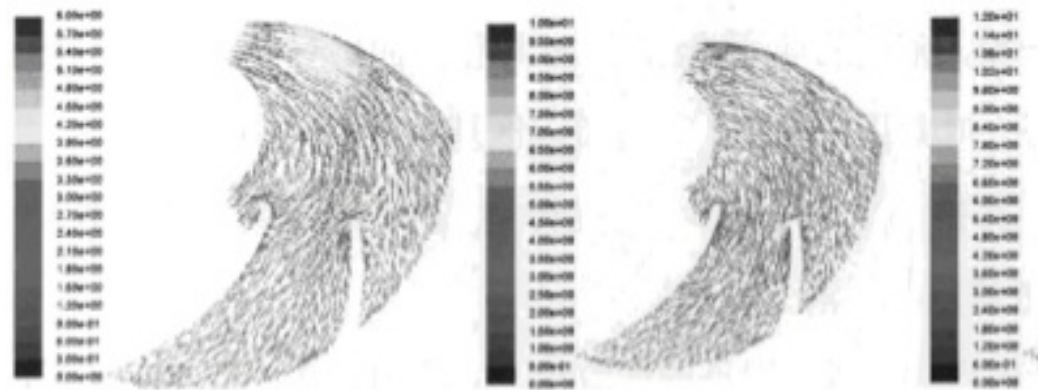

$$
\mathrm{Q}=10 \mathrm{~m}^{3} / \mathrm{h}
$$

$\mathrm{Q}=25 \mathrm{~m}^{3} / \mathrm{h}$

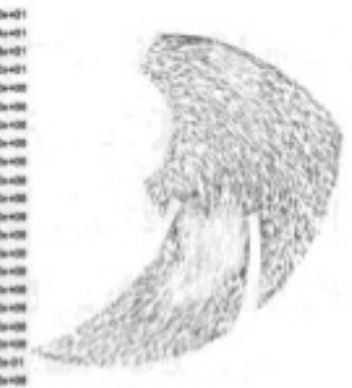

Fig. (6). The relative velocity distribution on the cross section under different working conditions based on plan 3 .
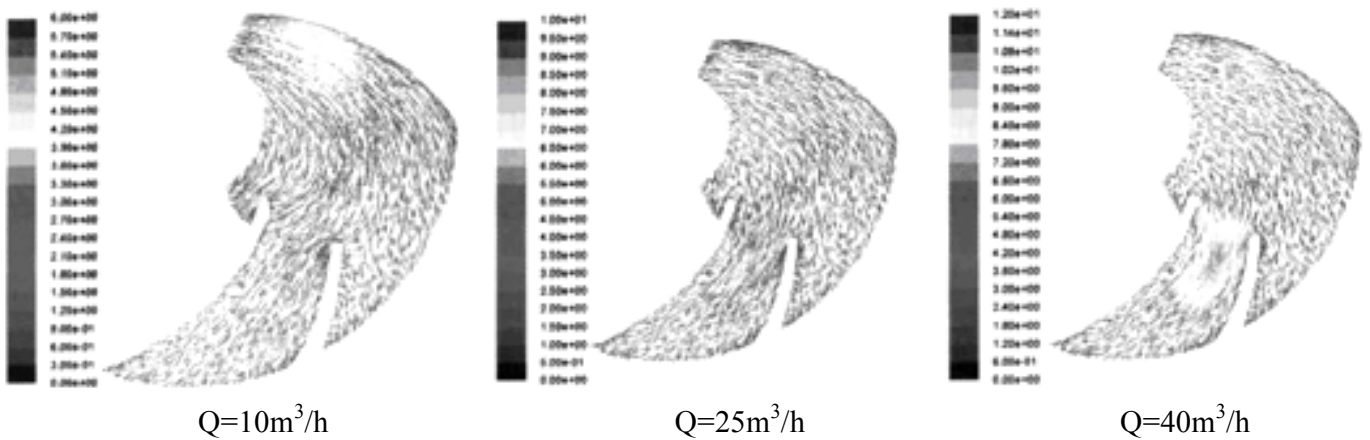

Fig. (7). The relative velocity distribution on the cross section under different working conditions based on plan 4.

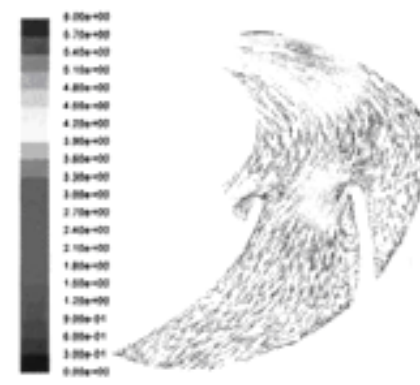

$\mathrm{Q}=10 \mathrm{~m}^{3} / \mathrm{h}$

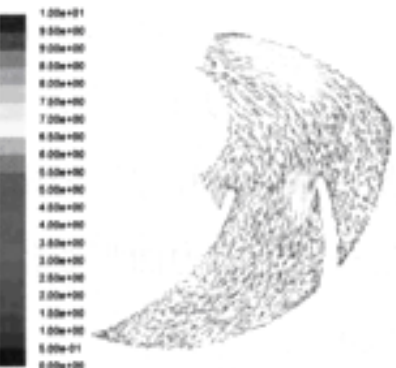

$\mathrm{Q}=25 \mathrm{~m}^{3} / \mathrm{h}$

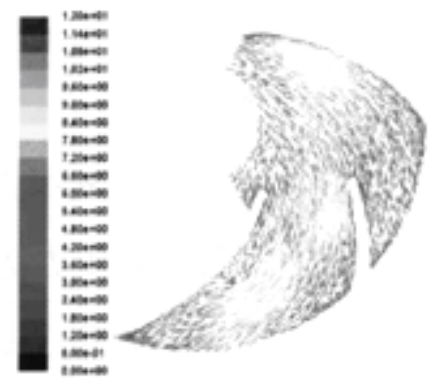

$\mathrm{Q}=40 \mathrm{~m}^{3} / \mathrm{h}$

Fig. (8). The relative velocity distribution on the cross section under different working conditions based on plan 5. 
still have transverse flow from long blade suction surface to the pressure side of short blades. There doesn't exist low speed wake zone in export of suction surface for long blades under each working condition.

For the impeller in plan 4 , the flow regularity in impeller passage is in basic accordance with that in plan 3. The difference is the flow velocity becomes larger than that in plan 3 , because the short blades have offset toward pressure surface of long blades.

For the impeller in plan 5, the flow regularity in impeller passage is basically in accordance with that in plan 3 and plan 4 . The difference is that it increases the flow velocity near import of suction surface for long blades, while the high speed flow appears around in suction side near the head of short blades. But for the position of impeller outlet, it's flow is more well-distributed than that in plan 3 and plan 4.

\subsubsection{The Static Pressure Distribution}

For five impellers, the static pressure distribution on the cross section under different working conditions is shown as in Figs. (7-11). According to analyzing on static pressure distribution under different working conditions, the analysis results are given as follows.

As can be seen from the Figs. (9-13), under different working conditions, maximum static pressure exists near the blade or long blade pressure side for each impeller.

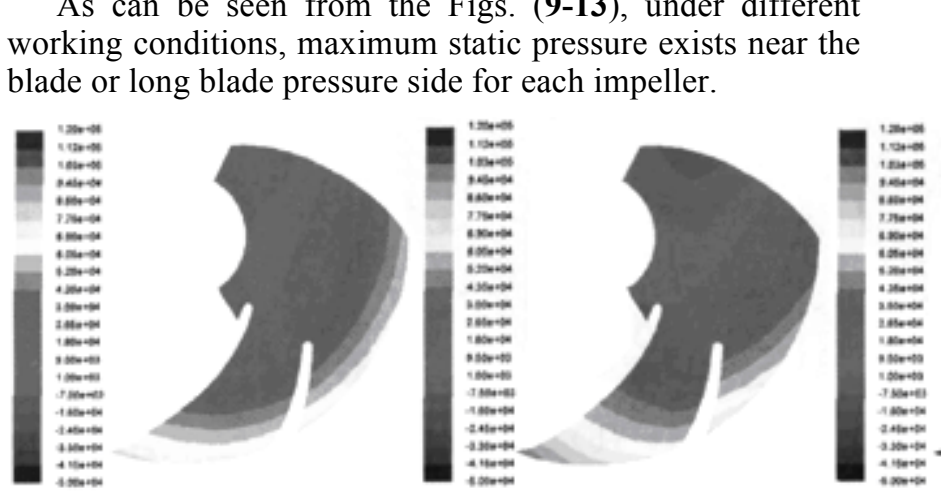

$\mathrm{Q}=10 \mathrm{~m}^{3} / \mathrm{h} \mathrm{Q}=25 \mathrm{~m}^{3} / \mathrm{h} \mathrm{Q}=40 \mathrm{~m}^{3} / \mathrm{h}$

Fig. (12). Static pressure distribution on the cross section for plan 4 .

For plan 1, the static pressure distribution is relatively well-distributed and regular under different working conditions. Under the small flow conditions, the static pressure isoline is almost a concentric circular arc with impeller near nozzle. Under the heavy flow conditions, the

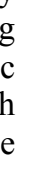

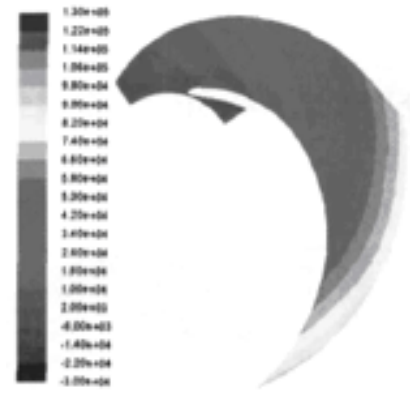

$\mathrm{Q}=10 \mathrm{~m}^{3} / \mathrm{h}$

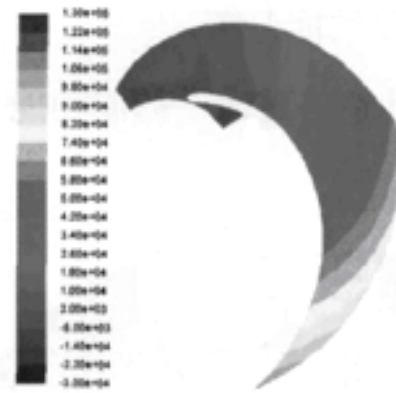

$\mathrm{Q}=25 \mathrm{~m}^{3} / \mathrm{h}$

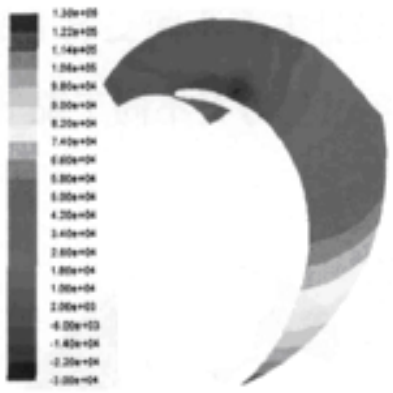

$\mathrm{Q}=40 \mathrm{~m}^{3} / \mathrm{h}$

Fig. (9). Static pressure distribution on the cross section for plan 1 .
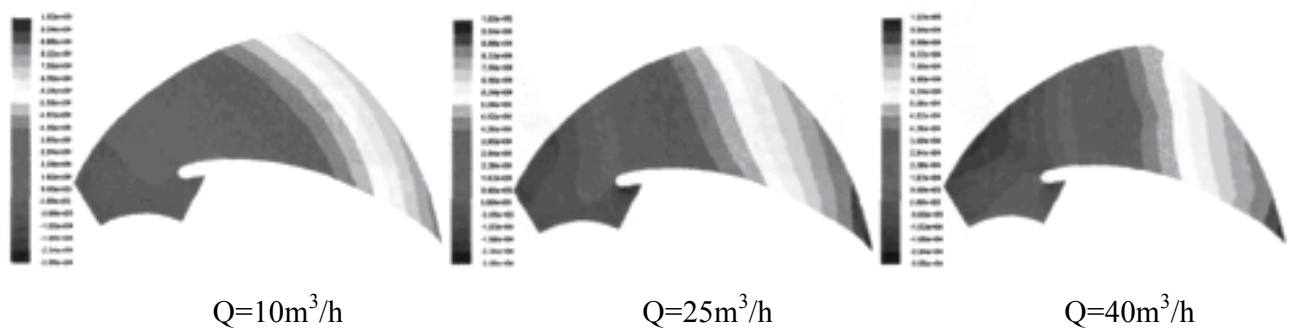

Fig. (10). Static pressure distribution on the cross section for plan 2.

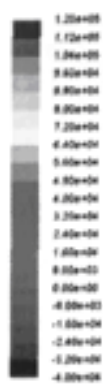

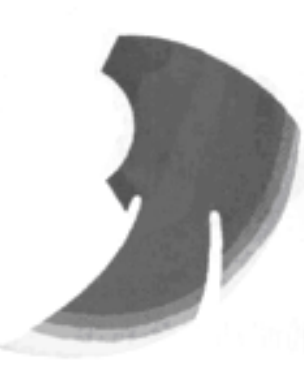

$\mathrm{Q}=10 \mathrm{~m}^{3} / \mathrm{h}$

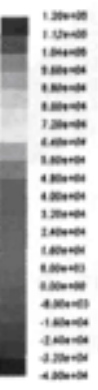

=

$\mathrm{Q}=25 \mathrm{~m}^{3} / \mathrm{h}$ 


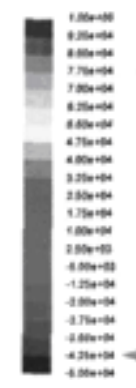

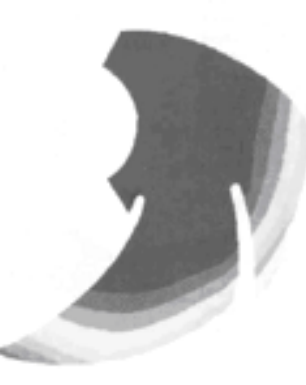

$\mathrm{Q}=10 \mathrm{~m}^{3} / \mathrm{h}$
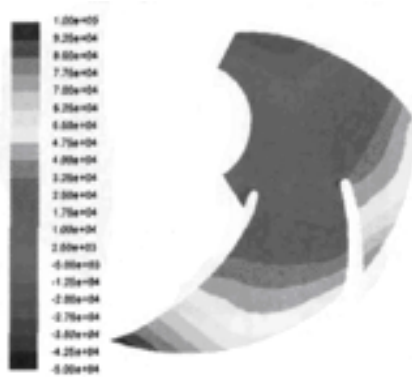

$\mathrm{Q}=25 \mathrm{~m}^{3} / \mathrm{h}$
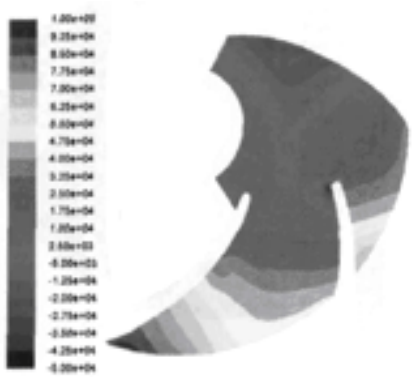

$\mathrm{Q}=40 \mathrm{~m}^{3} / \mathrm{h}$

Fig. (13). Static pressure distribution on the cross section for plan 5 .

static pressure distribution is less regular from inlet to middle position in passageway, the minimum static pressure exists in head of blades near pressure side.

For plan 2, the static pressure distribution is relatively well-distributed and regular under the small flow conditions in passageway. Under the design flow conditions the static pressure distribution is less regular, especially existed in the blade pressure surface near outlet. Meanwhile the minimum pressure area expanded in the suction side is near blade head. Under the heavy flow conditions, the static pressure distribution is seriousally uneven in the blade pressure surface near outlet.

The regularities of static pressure distribution is basically the same for that in plan 3, plan 4 and plan 5. It is the most regular under the small flow conditions, and it is the most irregular under the heavy flow conditions. The minimum static pressure exists at front position of the suction surface for the long blades and the suction side of blade head for short blades. But there are slightly different among the three impellers. The static pressure is minimum in inlet for plan 3 , and it is maximum for that of plan 5. For the static pressure distribution in the whole flow passage under each flow conditions, there is the worst for plan 3 and the best for plan 5.

\subsubsection{The Conclusion of Comparison Analysis}

According to analysis of relative velocity distribution and static distribution under different flow conditions for the above each scheme, the conclusion of comparison analysis can be obtained as follow. The impeller in plan1 is ideal, which was designed to adopt low specific speed design method. The impeller in plan 2 is not so good, which was designed to adopt speed coefficient method design. The inner flow of the impeller is improved in plan 3, plan 4 and plan 5, which was designed to adopt splitter blades method design. Among the five impeller the impellers in plan 1 and plan 5 are more ideal.

\subsubsection{External Characteristic Experiment}

To test and verify the correctness of simulation results, the external characteristic experiment was performed for different pump, which adopted different impellers and the same volute. The performance curve is shown in Fig. (14). According to the graph, all the design have reached the design requirements. The head curve has relatively steep fall for plan 1, and it is slightly lower for plan 3 . According to efficiency curve, the efficiency is the highest for the impeller in plan 5 among the five impellers, especially under the heavy flow conditions. So simulation results are in accordance with the experimental results.

\section{CONCLUSION}

This work reveals the inner flow pattern of the five impellers, and gives several comparing performances of the five impellers designed by different design methods. The conclusions can be summarized as follows:

1. It avails improving the uniformity of velocity distribution and pressure distribution inside the impeller flow channel for the short blades to offset toward the suction side of the long blades and reducing the hydraulic loss within impeller. To a certain extent, the structure of jet-wake flow is effectively improved by this structure, meanwhile it have the effect on scouring away the wake.

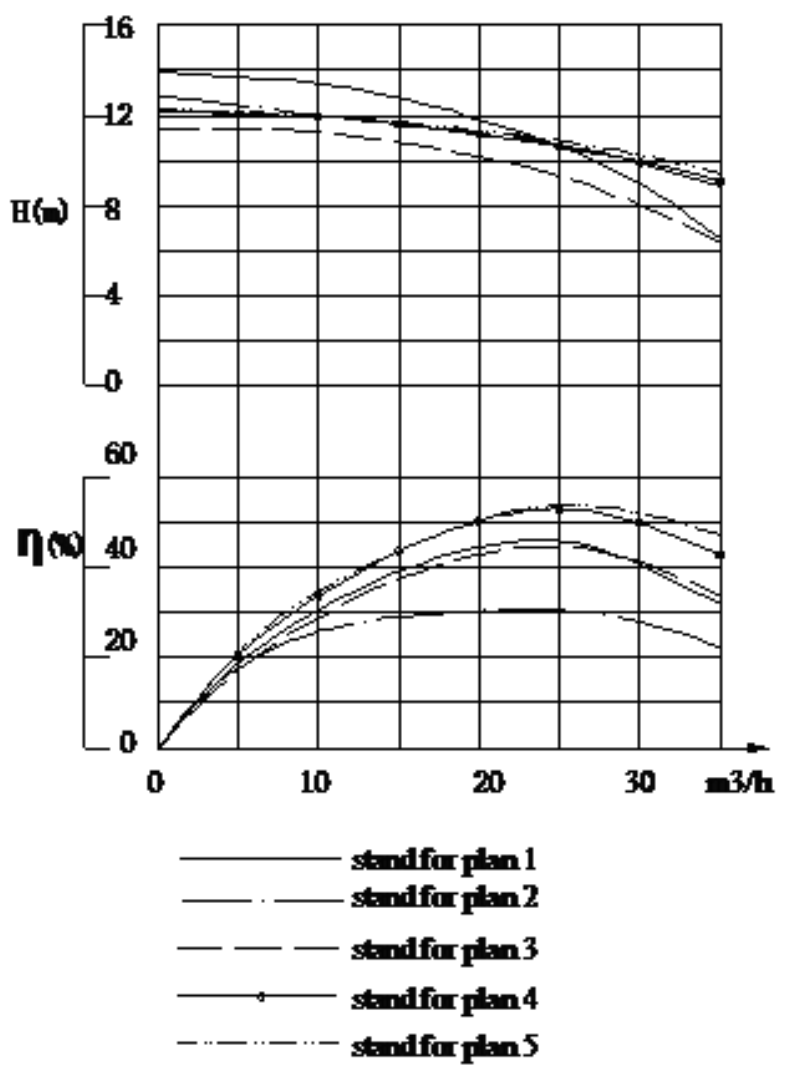

Fig. (14). Performance curve on five centrifugal pump. 
2. No overload performance of pump can be implemented easily by adapting the impeller in plan 1. For pumps whose performance doesn't require no overload performance, it is the best scheme adapting the impeller in plan 5 .

3. Internal flow presents non-axisymmetrical flow for centrifugal pump with splitter blades. Under the same conditions, the flow field has large difference in different slot position for the same impeller. Relative velocity is lower on the pressure surface side and higher on suction surface side. Relative speed increases first then reduces again from pressure surface to suction surface.

\section{CONFLICT OF INTEREST}

The authors confirm that this article content has no conflict of interest.

\section{ACKNOWLEDGEMENTS}

The authors are thankful to professor wan-yong zhao for discussion and comments on non-axisymmetrical flow for centrifugal pump with splitter blades.

\section{REFERENCES}

[1] Z. Zhu, "Theory and Design Application on Low Specific Speed and High Speed Centrifugal Pump," Haifeng Wang ,ed. ,Mechanical industry press, Beijing, pp. 65-84, 2008.

[2] Y. Choi, J. Kurokawaj, and J. Matsui, "Performance and Internal Flow Characteristics of a Very Low Specific Speed Centrifugal Pump," J. Fluid Eng, vol. 128, pp.341-349, 2006.

[3] F. E. John, and J. B. Franzini, "Fluid Mechanics with Engineering Applications," McGraw-Hill Companies Inc, 2002.

[4] T. Shigemitsu, J. Fukutomi, K. Kaji, and T. Wada, "Unsteady internal flow conditions of mini-centrifugal pump with splitter blades," Journal of Thermal Science, vol. 22, no. 1, pp.86-91, 2013.

[5] G. Kergourlay, M. Younsi, F. Bakir, and R. Rey, "Influence of Splitter Blades on the Flow Field of a Centrifugal Pump: TestAnalysis Comparison," International Journal of Rotating Machinery, vol. 58, pp.1-13, 2007.

[6] F. Wang, "The analysis of computational fluid dynamics, the theory and application of CFD," Qinghua university Press, Beijing, pp.120-138, 2004. 